\title{
The Degree of Practicing Knowledge Management Concept among Public Secondary Schools' Principals in Kuwait from Their Point of View
}

\author{
Fatima Abdul Reda Buftain \\ PO box 47082 , Kuwait 47082
}

\begin{abstract}
The present study aimed at identifying the degree of practicing knowledge management concept among public secondary schools' principals in Kuwait from their point of view. The study population consisted of community consisted of public secondary schools' principals in Kuwait for the first semester (2020/2021). Whereas the study sample consisted of (60) public secondary schools' principals. Descriptive Surveying approach was developed, in which the questionnaire consisted of (40) statements. It was found that the degree of practicing knowledge management concept among public secondary schools' principals in Kuwait was moderate. It was also found that there were significant differences that can be attributed to gender, it came in favor of males and there were no significant differences that can be attributed to academic qualification. Based on the results, it was recommended to re-consider the implementation of knowledge management concept
\end{abstract}

Keywords: Knowledge Management, Secondary Schools, Secondary School Principals, Kuwait

DOI: $10.7176 / \mathrm{JEP} / 12-5-10$

Publication date: February $28^{\text {th }} 2021$

\section{Introduction}

Knowledge Management concept is one of the modern concepts of the management sciences. In the last two decades, there has been an increased interest in it, this led to the emergence of many definitions for this concept, where they differed according to the different disciplines of researchers and their different views. The concept is still in the stage of development and discovery. Chou Yeh, 2005 indicates that the roots of the field of knowledge management extend to economic thought, which was widespread during the nineteenth century, it examines the factors of production such as capital, land, labor and knowledge, which represent the determinants of a country's economic growth and the success of organizations.

Since knowledge management has become a good system for management, educational organizations have tried to adopt this concept, this is why these organizations strive to implement knowledge management concept by building knowledge societies through the use of modern technological methods (Elayyan, 2008).

Knowledge management in schools works on developing commitment and enthusiasm at work, it increases the ability to make educational decisions and solve problems, and it develops an organizational memory for schools. Knowledge management in schools shares the modern vision of education and pedagogy by looking at the demand as the core of the educational process. Therefore, it requires increasing the added value in schools, through knowledge management strategy and setting a clear vision of the value that schools seek to add. Based on this vision, the objectives, activities and processes will be formulated through which information will be collected, processed and used in the overall operations and activities that take place within the school. (Tashkendi, 2008).

The implementation of knowledge management in modern organizations is the most important way to achieve excellence and leadership in today's world. When an organization is directed towards the knowledge categories, obtains and disseminates them at all administrative levels, develops its quest for investment in owning new knowledge, and employs the knowledge it possesses with the required efficiency and effectiveness, and promotes the best practices, it will lead towards reaching a stage of excellence (Hamshari, 2012).

The traditional management and traditional competition variables and its tools are no longer effective in upgrading organizations in the era of knowledge and information technology, experienced by organizations, and the knowledge power, in return, has become one of the most important assets of the organization, since it's been described as the most important resource and strategic source in building the competitive advantage of the organization, which is considered as a tool for creating added value. Its importance lies in being easily obtained and used to generate new knowledge at a lower cost.

\section{Statement of the problem and study's questions:}

The success of educational organizations requires keeping pace with what is new in management and in their ability to employ them in their tasks and activities through which they obtain outcomes that contribute to the success of the educational institution. This will ensure that these organizations reach advanced levels in pioneering and creativity. When school principals develop their thoughts and perspectives towards knowledge 
management, they can seize the initiative and translate it into reality with distinctive results.

Based on the above-mentioned information, the study's problem is represented by the following questions:

Q.1 What is the degree of practicing knowledge management concept among public secondary schools' principals in Kuwait from their point of view?

Q.2 Are there any significant differences at $(\mathrm{a}=0.05)$ in the degree of practicing knowledge management concept among public secondary schools' principals in Kuwait from their point of view, which can be attributed to gender and academic qualification?

\section{Study's objectives}

The present study aimed at identifying the degree of practicing knowledge management concept among public secondary schools' principals in Kuwait from their point of view. It also aimed at identifying whether there are any significant differences at $(\mathrm{a}=0.05)$ in the degree of practicing knowledge management concept among public secondary schools' principals in Kuwait from their point of view, which can be attributed to gender and academic qualification.

\section{Study's significance}

- Hopefully, the present study will enable the following authorities to benefit from its results:

- The present study has theoretical significance: It lies in the importance of the scientific knowledge through its findings, in terms of the relationship between knowledge management and its implementation among secondary school principals in Kuwait, given that this variable has a clear significance in the importance of practicing knowledge management in secondary schools in general and in Kuwait in particular.

- Based on the researchers' knowledge, it is considered a pioneering study in Kuwait that could fill a shortage in the Arabic library.

- The present study has practical significance: The results of this study can restrict secondary school administrations to raise the level of knowledge management implementation in their schools and reduce the negative effects of that.

\section{The study's definitions:}

5.1 Knowledge Management:

Knowledge Management is defined at the level of organizations and societies. Knowledge Management refers to "those efforts that are made to accomplish and complete the various steps and functions in knowledge acquisition, gaining, distribution, delivery, interpretation, employment and investment."

\subsection{Knowledge Management Applications:}

A set of programs and systems to activate the role of knowledge management in organizations.

\subsection{Secondary School Principals:}

They are the officials responsible for managing schools, especially the secondary school level, in public schools.

\section{Study's limits:}

-Thematic limits: This study shed a light on the degree of practicing knowledge management concept among public secondary schools' principals in Kuwait from their point of view.

- Human limits: This study sampled public secondary school principles.

- Spatial limits: This study was conducted in public secondary school in Kuwait

- Temporal limits: This study was conducted during the academic year 2020/2021.

\section{Study's Determinants:}

- The extent of the validity and reliability of the questionnaire

- The accuracy and objectivity of the response of the sampled members

- The results of this study are only to be generalized in communities similar to the community of this study.

\section{Previous Studies:}

Al-Sarhani (2013), aimed at identifying the status quo of knowledge management applications in the two study societies: Jubail Royal Commission and Kayan Petrochemicals Company in terms of their trends and opinions, the sources of knowledge used, the practices of knowledge management processes implemented, the availability of techniques and means, the use of systems, identification of its obstacles, advantages, and requirements, the reasons that require its implementation, and the identification of employee satisfaction, in addition to the identification of the differences between the two study societies, and providing guidelines for knowledge sharing 
that are applicable in the study societies and other similar societies. It also aimed at presenting suggestions and recommendations to define the best ways for knowledge management applications in the two study societies, moreover, benchmarking was used through reviewing the best methods for implementing knowledge management applications and through reviewing the experiences of some international organizations and their methods of implementing these applications as tools to identify gaps and inconsistencies in performance, as well as for the improvement and development of many processes and strategies in organizations and their development.

Al Fares (2010), aimed at identifying the role of knowledge management in improving and enhancing the level of performance. It was applied on ten modern companies established in accordance with the Investment Promotion Law in 1991, and the data were mainly collected through a questionnaire prepared for this purpose with some limited interviews carried out on a period of five years (2003-2007), the study concluded that the results have confirmed the existence of a strong correlation between knowledge management and performance. This allowed the researcher to draw applicable conclusions and to benefit from them, and allowed him to make recommendations that would contribute efficiently and effectively in improving the performance of the companies underwent this study, and all similar organizations, both organizationally and technically.

Othman (2010), aimed at identifying the attitudes of public secondary school principals towards the implementation of knowledge management in the northern governorates in Palestine, in addition to presenting the impact of gender, years of administrative experience, specialization, academic qualification, school location and governorate location variables towards implementing knowledge management. The study population consisted of all public secondary school principals in the northern governorates of Palestine, in which consisted of (640) female and male principals. A random stratified sample of (229) was selected. To achieve the objectives of the study, a questionnaire was developed and consisted of (60) statements distributed to (8) dimensions: (Understanding Knowledge Management Concept, The Appropriate Timing for Knowledge, Administrative Processes and Planning, Organizing Knowledge and Identifying its Sources, Organizational Communication, Decision-Making, Planning, and Knowledge Management Objectives). It was found that the attitudes of public secondary school principals towards the implementation of management knowledge in the northern governorates of Palestine was positive. It was also found that there were no significant differences in the degree of attitudes of public secondary school principals towards the implementation of knowledge management in the northern governorates of Palestine that can be attributed to gender, years of administrative experience, specialization, academic qualification, and school location. Whereas, there were significant differences in the degree of attitudes of public secondary school principals towards the implementation of knowledge management in the northern governorates of Palestine that can be attributed to governorate's location, in "Understanding Knowledge Management Concept" dimension, between northern and central governorates in the West Bank which came in favor of the northern governorates in the West Bank, Furthermore, it was found that there were significant differences in the degree of attitudes of public secondary school principals towards the implementation of knowledge management in the northern governorates of Palestine that can be attributed to the governorate's location in "Administrative Processes and Planning" between the southern and central governorates in the West Bank which came in favor of the southern governorates in the West Bank, and between the northern and central governorates in the West Bank and came in favor of the northern governorates in the West Bank. Moreover, there were significant differences in the degree of attitudes of public secondary school principals towards the implementation of knowledge management in the northern governorates of Palestine that can be attributed to the governorate's location in the total degree between the southern and central governorates in the West Bank and came in favor of the southern governorates in the West Bank, and between the northern and central governorates in the West Bank, and came in favor of the northern governorates in the West Bank.

Salem (2007), aimed at identifying the concept of knowledge management, its entries, processes and determinants, it also aimed at developing a proposed conception for developing administrative performance using knowledge management approach in public secondary schools in Egypt. A descriptive analytical approach was adopted to understand and analyze the different aspects of the phenomenon and explain the correlations between them. The study population consisted of: principals, assistant principals, and first teachers in some public secondary schools in the governorates of (Cairo, Sharkia, Qena). A questionnaire was developed as the study tool. It was found that there were significant differences in the responses of the sampled members in regard to the extent to which the school administration in public secondary schools seeks to acquire knowledge. It was also found that there were significant differences in the responses of the sampled members in regard to the extent of the school administration in public secondary schools seeking to store and retrieve knowledge, furthermore, there were significant differences in the responses of the sampled members in regard to the extent of the administration's efforts in the public secondary schools to transfer knowledge, and there were significant differences in the responses of the sampled members in regard to the extent of the school administration's efforts in the public secondary schools to apply knowledge.

The previous studies came somewhat close to these study variables. This study is distinguished from 
previous studies by dealing with the degree of practicing knowledge management concept in secondary schools in Kuwait.

\section{Study's Approach:}

A descriptive Surveying approach was adopted. It was adopted to identify the degree of practicing knowledge management concept among public secondary schools' principals in Kuwait from their point of view. By referring to the previous studies related to the subject of the study, then collecting data using the study tool and statistically analyzing it to answer the study questions.

\section{Study's Population and Society:}

The population is represented by all principals working at 130 public secondary schools in Kuwait. A sample of 60 female and male principals was selected through random sampling method. Data about that is displayed below in table (1)

Table (1): Distribution of the study's respondents in accordance with (gender, academic qualifications)

\begin{tabular}{|l|l|r|r|}
\hline Variable & Category & Frequency & Percentage \\
& Male & 32 & $53.3 \%$ \\
\cline { 2 - 4 } & Female & 28 & $46.7 \%$ \\
\cline { 2 - 4 } & Total & $\mathbf{6 0}$ & $\mathbf{1 0 0 \%}$ \\
\hline \multirow{2}{*}{$\begin{array}{l}\text { Academic } \\
\text { Qualifications }\end{array}$} & Bachelor's Degree & 44 & $73.3 \%$ \\
\cline { 2 - 4 } & Post Graduate Degrees & 16 & $26.7 \%$ \\
\cline { 2 - 4 } & Total & 60 & $100.0 \%$ \\
\hline
\end{tabular}

\section{Study's Instrument:}

A questionnaire was developed after reviewing the relevant studies. This questionnaire consisted of (40) statements that aimed at identifying the degree of practicing knowledge management concept among public secondary schools' principals in Kuwait from their point of view.

\section{Validity of the Instrument:}

To measure the validity of the questionnaire, Content Validity method was used. The initial questionnaire was passed to experts in the educational field. Based on experts' opinions, the questionnaire was modified.

\section{Reliability of the Questionnaire:}

To measure the reliability of the questionnaire, Cronbach alpha coefficient was used. the values ranged between (0.84 and 0.93 ) which is acceptable.

\section{Criteria for classifying means:}

In order to describe the results, the means of the study tool were classified into three categories: low, medium and high., a response ladder was adopted using the following formula:

Category $=($ Highest limit of scale (5) - Lowest limit of scale (1)) $/ 3$

Category $=(5-1) / 3=1.33$

In which: $1.00-2.33$ : low

$$
2.34-3.67 \text { : moderate } \quad 3.68 \text { and above: high }
$$

\section{Statistical analysis:}

Different statistical analysis methods were used to analyze data and to answer the study two questions such as means, standard deviation and t-test.

\section{Results and discussion:}

16.1. Results and discussion related to the study's first question: Q.1 What is the degree of practicing knowledge management concept among public secondary schools' principals in Kuwait from their point of view?

To answer this question, means and standard deviations for the degree of practicing knowledge management concept among public secondary schools' principals in Kuwait from their point of view. These values for each statement are captured in table (2) below 
Table (2): The degree of practicing knowledge management concept among public secondary schools' principals in Kuwait from their point of view.

\begin{tabular}{|c|c|c|c|c|c|}
\hline $\begin{array}{l}\text { Statement } \\
\text { Number }\end{array}$ & Rank & Statement & Mean & Std. & Level \\
\hline 29 & 1 & $\begin{array}{l}\text { I classify and document data and information in a way that is } \\
\text { easy to be retrieved. }\end{array}$ & 4.17 & 0.99 & High \\
\hline 4 & 2 & $\begin{array}{l}\text { I create a system of incentives to encourage teachers to } \\
\text { create knowledge. }\end{array}$ & 4.13 & 1.07 & High \\
\hline 21 & 2 & $\begin{array}{l}\text { I support knowledge integration in all management } \\
\text { activities. }\end{array}$ & 4.13 & 0.62 & High \\
\hline 28 & 4 & $\begin{array}{l}\text { I use the computer to store the needed information to run the } \\
\text { school effectively. }\end{array}$ & 4.12 & 0.80 & High \\
\hline 38 & 5 & $\begin{array}{l}\text { I participate in scientific seminars and study days held by } \\
\text { different educational organizations to exchange knowledge. }\end{array}$ & 4.08 & 0.79 & High \\
\hline 36 & 6 & $\begin{array}{l}\text { I encourage the use of media to transfer knowledge to } \\
\text { teachers. }\end{array}$ & 4.00 & 0.99 & High \\
\hline 13 & 7 & $\begin{array}{l}\text { I develop teachers' research skills in knowledge circulation } \\
\text { and transfer. }\end{array}$ & 3.98 & 1.19 & High \\
\hline 5 & 8 & $\begin{array}{l}\text { I support creative ideas to develop teachers' competitive } \\
\text { advantage. }\end{array}$ & 3.93 & 1.78 & High \\
\hline 7 & 9 & $\begin{array}{l}\text { I open horizons of research, experimentation and creative } \\
\text { thinking to teachers. }\end{array}$ & 3.85 & 1.21 & High \\
\hline 16 & 10 & $\begin{array}{l}\text { I support creative teachers to share their knowledge with } \\
\text { others. }\end{array}$ & 3.82 & 0.98 & High \\
\hline 18 & 11 & $\begin{array}{l}\text { I employ technology and scientific techniques to solve } \\
\text { school problems. }\end{array}$ & 3.80 & 0.84 & High \\
\hline 8 & 12 & I encourage intellectual diversity among the teachers. & 3.72 & 1.18 & High \\
\hline 17 & 13 & $\begin{array}{l}\text { I make sure to have sound and correct information to make } \\
\text { good decisions. }\end{array}$ & 3.68 & 1.31 & High \\
\hline 34 & 13 & $\begin{array}{l}\text { I use rewards to encourage teachers to convert implicit } \\
\text { knowledge (in their minds) into explicit (written) } \\
\text { knowledge. }\end{array}$ & 3.68 & 1.31 & High \\
\hline 20 & 15 & $\begin{array}{l}\text { I benefit from the available knowledge in developing } \\
\text { developmental plans. }\end{array}$ & 3.62 & 0.49 & Moderate \\
\hline 37 & 15 & $\begin{array}{l}\text { I foster a supportive environment for knowledge exchange } \\
\text { and ideas transfer among teachers. }\end{array}$ & 3.62 & 0.49 & Moderate \\
\hline 32 & 17 & $\begin{array}{l}\text { I keep brief and written reports of knowledge organization } \\
\text { and storage. }\end{array}$ & 3.60 & 0.92 & Moderate \\
\hline 24 & 18 & $\begin{array}{l}\text { I involve parents in school matters, especially those related } \\
\text { to the students. }\end{array}$ & 3.57 & 1.08 & Moderate \\
\hline 26 & 19 & $\begin{array}{l}\text { I implement training programs that develop teachers' } \\
\text { knowledge. }\end{array}$ & 3.53 & 0.81 & Moderate \\
\hline 9 & 20 & $\begin{array}{l}\text { I ensure the accuracy and integrity of the information that } \\
\text { teachers exchange with others. }\end{array}$ & 3.43 & 1.23 & Moderate \\
\hline 12 & 21 & I share knowledge through formal and informal means. & 3.40 & 1.64 & Moderate \\
\hline 14 & 22 & $\begin{array}{l}\text { I use educational handouts to inform teachers of the } \\
\text { available knowledge. }\end{array}$ & 3.37 & 1.13 & Moderate \\
\hline 31 & 23 & $\begin{array}{l}\text { I keep brief and written reports of knowledge organization } \\
\text { and storage }\end{array}$ & 3.35 & 0.48 & Moderate \\
\hline 22 & 24 & I strive to nurture teachers' self-growth. & 3.30 & 1.24 & Moderate \\
\hline 30 & 24 & $\begin{array}{l}\text { I use the new information to achieve a competitive position } \\
\text { among neighboring schools. }\end{array}$ & 3.30 & 0.96 & Moderate \\
\hline 25 & 26 & $\begin{array}{l}\text { I allow students to present their ideas in a democratic } \\
\text { climate. }\end{array}$ & 3.27 & 0.45 & Moderate \\
\hline 33 & 26 & $\begin{array}{l}\text { I categorize the available knowledge in tables, diagrams, or } \\
\text { images for easy interpretation and reference. }\end{array}$ & 3.27 & 0.45 & Moderate \\
\hline 40 & 26 & $\begin{array}{l}\text { I use the school's internal mail to share knowledge with } \\
\text { Ministry of Education officials. }\end{array}$ & 3.27 & 0.45 & Moderate \\
\hline
\end{tabular}




\begin{tabular}{|r|r|l|l|l|l|}
\hline \multicolumn{1}{|l|}{$\begin{array}{l}\text { Statement } \\
\text { Number }\end{array}$} & Rank & Statement & Mean & Std. & Level \\
\hline 27 & 29 & I use new knowledge to achieve the mission of my school & 3.25 & 0.54 & Moderate \\
\hline 11 & 30 & $\begin{array}{l}\text { I contribute to facilitating teachers access to information to } \\
\text { benefit from it in a timely manner. }\end{array}$ & 3.23 & 0.98 & Moderate \\
\hline 19 & 31 & $\begin{array}{l}\text { I benefit from the skills of the librarian in coding and storing } \\
\text { knowledge. }\end{array}$ & 3.22 & 1.01 & Moderate \\
\hline 39 & 33 & I try new ideas to solve problems in school. & 3.22 & 0.56 & Moderate \\
\hline 1 & 34 & $\begin{array}{l}\text { I rely internet to exchange knowledge. } \\
\text { knowledge. }\end{array}$ & 3.18 & 1.19 & Moderate \\
\hline 15 & 35 & $\begin{array}{l}\text { I look for sources of knowledge inside and outside the } \\
\text { school. }\end{array}$ & 3.02 & 0.79 & Moderate \\
\hline 6 & 36 & $\begin{array}{l}\text { I hold workshops and seminars related to knowledge in } \\
\text { school. }\end{array}$ & 3.00 & 0.69 & Moderate \\
\hline 35 & 37 & $\begin{array}{l}\text { I publish a group of educational articles on the directorate's } \\
\text { website to contribute to the transfer of knowledge. }\end{array}$ & 2.95 & 1.44 & Moderate \\
\hline 23 & 38 & $\begin{array}{l}\text { I use self-assessment method with the best strategies the } \\
\text { students learn from during the teaching process. }\end{array}$ & 2.92 & 0.79 & Moderate \\
\hline 10 & 39 & $\begin{array}{l}\text { I communicate with my fellow principals to exchange } \\
\text { opinions and ideas. }\end{array}$ & 2.88 & 0.80 & Moderate \\
\hline 2 & 40 & $\begin{array}{l}\text { I rely on the electronic database to organize information } \\
\text { related to school matters. }\end{array}$ & 2.50 & 1.26 & Moderate \\
\hline
\end{tabular}

Based on the results shown in table (2), the degree of practicing knowledge management concept among public secondary schools' principals in Kuwait from their point of view is moderate. The overall mean is (3.49) and the total standard deviation is $(0.08)$. The result may be attributed to the nature and mechanisms of work performed by public secondary schools' principals in Kuwait, who may face some difficulties and lack of clarity in terms of knowledge management, despite the keenness of the education departments in Kuwait to provide an appropriate environment for principals and to encourage them to join training programs related to knowledge management and its applications, in order to motivate them to work as a group, and participate in decisionmaking so that they realize the importance of the work they undertake and that they have an active role in the success of any work inside the school and to develop their creativity and innovation and motivate them to contribute to the development of work.

Based on the results shown in table (2), statement (29) "I classify and document data and information in a way that is easy to be retrieved." ranked first with a mean of (4.17) which is high. This result may be attributed to the focus of the Ministry of Education in Kuwait on the technological infrastructure in the previous three stages and on the availability of modern information technology to manage knowledge in many forms such as: the information network, the intranet, the Internet, the browsers program, and the data warehouses of public secondary schools in Kuwait, which facilitates and accelerates knowledge management in the country.

Based on the results shown in table (2), statement (4) "I create a system of incentives to encourage teachers to create knowledge" and statement (21)" I support knowledge integration in all management activities." ranked first with a mean of (4.13) which is high. This result may be attributed to the attention public secondary school principals in Kuwait pertains to human element through caring for them, setting up a special system of incentives, paying attention to the organizational culture that supports knowledge in terms of generating, sharing and using it, providing the necessary creative means for knowledge individuals, and preparing the necessary infrastructure for knowledge in terms of computers, software and the necessary communication means.

Based on the results shown in table (2), statement (10) "I communicate with my fellow principals to exchange opinions and ideas." ranked before the last with a mean of (2.88) which is moderate. This result may be attributed to the lack of time principals have in order to communicate with other fellow principals to exchange views and ideas.

Based on the results shown in table (2), statement (2) "I rely on the electronic database to organize information related to school matters" ranked last. with a mean of (2.50) which is moderate. This result may be attributed to the dependence of some principals on memorization and paper-based information more than the use of electronic database. 
16.2. Results and discussion related to the study's second question: Q.2 Are there any significant differences at $(a=0.05)$ in the degree of practicing knowledge management concept among public secondary schools' principals in Kuwait from their point of view, which can be attributed to gender and academic qualification?

This question was answered as follows:

16.2.1 Gender variable:

The means and standard deviations for the estimates of the sampled members for the degree of practicing knowledge management concept among public secondary schools' principals in Kuwait, which can be attributed to gender was calculated, and a t-test was applied. These values are captured in table (3)

Table (3): Means and standard deviations for the estimates of the sampled members for the degree of practicing knowledge management concept among public secondary schools' principals in Kuwait, which can be attributed to gender and a t-test.

\begin{tabular}{|l|l|l|l|l|l|}
\hline Gender & Frequency & Means & Std & t & Sig \\
\hline Male & 32 & 3.51 & 0.06 & \multirow{2}{*}{2.189} & \multirow{2}{*}{0.033} \\
\cline { 1 - 5 } Female & 28 & 3.46 & 0.1 & & \\
\hline
\end{tabular}

Based on the results shown in table (3), there are significant differences in the means of the estimates of the sampled members for the degree of practicing knowledge management concept among public secondary schools' principals in Kuwait, which can be attributed to gender and came in favor of males with a mean of (3.51) compared to females with a mean of (3.46), according to t value of (2.189) and significance of (2.189). This result may be attributed to male interest in knowledge management and its applications to show its results in their work or to the fact that they have obtained training courses dealing with knowledge management and its applications.

16.2.2 Academic Qualification variable:

The means and standard deviations for the estimates of the sampled members for the degree of practicing knowledge management concept among public secondary schools' principals in Kuwait, which can be attributed to academic qualification was calculated, and a t-test was applied. These values are captured in table (4)

Table (4): Means and standard deviations for the estimates of the sampled members for the degree of practicing knowledge management concept among public secondary schools' principals in Kuwait, which can be attributed to academic qualification and a t-test.

\begin{tabular}{|l|l|l|l|l|l|}
\hline Academic Qualification & Frequency & Means & Std & $\mathrm{t}$ & $\mathrm{Sig}$ \\
\hline Bachelor's Degree & 44 & 3.48 & 0.08 & \multirow{2}{*}{1.111} & \multirow{2}{*}{0.271} \\
\cline { 1 - 4 } Post Graduate Degrees & 16 & 3.51 & 0.08 & & \\
\hline
\end{tabular}

Based on the results shown in table (4), there are no significant differences in the means of the estimates of the sampled members for the degree of practicing knowledge management concept among public secondary schools' principals in Kuwait, which can be attributed to academic qualification, according to t value of (1.111) and significance of (0.271). This result may be attributed to the nature of the study sample, which was relatively few, in the various academic qualifications, or they were all exposed to the same conditions with regard to knowledge management concepts and their applications.

\section{Recommendations:}

In the light of the study's results, the followings are recommended:

- The Ministry of Education to begin implementing knowledge management in public schools in general and in public secondary schools in Kuwait in particular.

- $\quad$ To reinforce positive trends towards the application of knowledge management in public secondary schools in Kuwait.

- The Ministry of Education to initiate the development of a suitable strategy for implementing knowledge management in the various educational institutions and schools in line with its capabilities.

- $\quad$ Spread the knowledge management culture, through:

- Upgrading the value and importance of knowledge in all aspects of school work.

- Supporting the value of teamwork to facilitate knowledge acquisition and dissemination.

- Emphasizing on the importance and value of knowledge when it comes to its dissemination and use, not in its preservation.

- Establishing appropriate incentive programs that encourage creativity and innovation at work.

- Activating the role of the school and various educational institutions in spreading the knowledge management culture.

- To conduct more field studies to verify the availability of knowledge management requirements in the various public secondary schools in Kuwait. 


\section{References}

- Al-Faris, Suleiman (2010). The Role of Knowledge Management in Increasing the Efficiency of Organizations' Performance (a field study on private manufacturing companies in Damascus). Damascus University Journal of Economic and Legal Sciences. 2(26). pp. 59-85.

- Al- Sarhani, Abdullah (2013). Knowledge Management Applications in the Public and Private Sectors in the Kingdom of Saudi Arabia. A comparative study on the Royal Commission for Jubail and the Saudi Kayan Petrochemical Company. 12. pp.264-292.

- Elayyan, Rebhi Mustafa. (2008). Knowledge House. Amman: Safaa House for Publishing and Distribution.

- Hamshari, Omar Ahmed (2012). Knowledge Management is the Path to Managing Excellence. Amman: Safaa House for Publishing and Distribution.

- Ching-Shan W.U. \& Hsu-Chun H. (2006). A Study of Knowledge Management in Elementary Schools: Advantageous Situations, Difficulties, and Strategies. Article written in Chinese. Bulletin of Educational Research. 2(52). pp 33-65.

- $\quad$ Othman, Allan Muhammad Khalil (2010). Attitudes of Government Secondary Schools Directorate towards the Application of Knowledge Management in the Northern Governorates of Palestine. Unpublished master's thesis. An-Najah National University, Palestine.

- Salem, Zakaria (2007). Knowledge Management is an Introduction to Developing Administrative Performance in Public Secondary Schools in Egypt. Unpublished master's thesis, Alexandria, Egypt.

- Tashkandi, Zakia Bint Malluh Qari Abdullah (2007). Knowledge Management: Its Importance and Application of its Operations from the Point of View of Directors of Departments and Administrative Supervisors at the Department of Education in Makkah Al-Mukarramah City and Jeddah Governorate. Unpublished Master Thesis, Umm Al-Qura University, Saudi Arabia. 